\title{
OPIOID AND NON-OPIOID STRESS ANALGESIA: ASSESSMENT OF TOLERANCE AND CROSS-TOLERANCE WITH MORPHINE ${ }^{1}$
}

\author{
JAMES W. LEWIS, * JACK E. SHERMAN, $\ddagger$ AND JOHN C. LIEBESKIND\& \\ ${ }^{*}$ Department of Psychology, $\ddagger$ Departments of Psychology and Anesthesiology, and $\S$ Department of Psychology and Brain Research Institute, \\ University of California, Los Angeles, Los Angeles, California 90024
}

\begin{abstract}
Opioid and non-opioid mechanisms of analgesia elicited by two kinds of footshock stress that differ only in temporal characteristics previously have been inferred on the basis of susceptibility to naloxone blockade. The present study sought further evidence on this point by comparing these two kinds of footshock analgesia for possible tolerance development and cross-tolerance with morphine. It was found that, with repeated exposure to stress, tolerance developed to naloxone-sensitive, but not naloxone-insensitive, stress analgesia. Furthermore, morphine-tolerant rats displayed crosstolerance to only the naloxone-sensitive form of footshock analgesia. Although prior exposure to both footshock paradigms potentiated morphine analgesia, less potentiation occurred in rats tolerant to the naloxone-sensitive footshock stress. Thus, cross-tolerance between morphine and this type of stress analgesia appears to occur in both directions. These findings are consistent with those using naloxone antagonism as a criterion for opioid mediation and support the conclusion that separate opioid and non-opioid mechanisms of stress analgesia exist.
\end{abstract}

Much evidence now can be cited to support the suggestion (Mayer et al., 1971) that portions of the medial brain stem serve normally to inhibit the perception of pain (for recent reviews, ef., Mayer and Price, 1976; Sherman and Liebeskind, 1980). Electrical stimulation of the periaqueductal gray matter (Mayer et al., 1971; Reynolds, 1969) and other, more rostral (Balagura and Ralph, 1973; Mayer and Liebeskind, 1974; Rhodes and Liebeskind, 1978) and caudal (Oleson et al., 1978; Oliveras et al., 1977) medial brain stem structures causes pronounced analgesia in conscious rats. Such analgesia can be attenuated by the opiate antagonist drug, naloxone (Akil et al., 1972, 1976b; Oliveras et al., 1977; Prieto et al., 1979), thereby implicating endogenous opioid peptides in its mediation (cf., Lewis et al., 1981). That opiate receptors and opioid peptides are found in moderate to high concentrations in brain areas important for stimulation-produced and opiate analgesia (cf., Mayer and Price, 1976; Watson et al., 1979; Yaksh and Rudy, 1978) lends further support to the hypothesis of an endogenous analgesia system originating in the medial brain stem.

Far less information is available concerning the circumstances normally activating this analgesia substrate. Reports that exposing rats to certain stressors causes analgesia were interpreted to mean that stress may be a physiological trigger for an intrinsic analgesia system

\footnotetext{
'This work was supported by National Institutes of Health Grant NS 07628 . J. W. L. was supported by Mental Health Training Program Grant MH 15345.
}

(Akil et al., 1976a; Bodnar et al., 1978a; Hayes et al., 1978). However, the opioid basis of such analgesia seemed uncertain in that some investigators found naloxone an effective stress-analgesia antagonist (Akil et al., 1976a; Amir and Amit, 1978; Bodnar et al., 1978a; Chesher and Chan, 1977; Cobelli et al., 1980), whereas others (Chance and Rosecrans, 1979b; Hayes et al., 1978) did not. The diversity of stressors used in these studies makes comparisons among them difficult and appears to be one factor responsible for the discrepant findings. We have reported recently (Lewis et al., 1980a) that a single stressor, inescapable footshock, elicits either a naloxone-sensitive or a naloxone-insensitive form of analgesia depending only on the shock's temporal parameters. Thus, neurochemically discrete (opioid and non-opioid) pain-inhibiting systems appear to exist that are accessed selectively by stressors having different quantitative and perhaps qualitative characteristics.

In addition to susceptibility to naloxone blockade, other criteria for the involvement of opioids in stress analgesia would include the development of tolerance to the analgesic effect of stress and the development of cross-tolerance between opiate and stress analgesia. Previous studies of stress analgesia examining both susceptibility to naloxone blockade and the development of tolerance to stress analgesia or cross-tolerance with opiate analgesia have tended to yield nonparallel results in that opioid involvement could be inferred according to one criterion but not another (Akil ct al., 1976a, 1978; Bodnar et al., 1978a, b; cf., however, Chesher and Chan, 
1977). The aim of the present investigation was to examine the questions of tolerance and cross-tolerance from the vantage point of the single stressor, inescapable footshock, varied parametrically to induce naloxone-sensitive and -insensitive forms of analgesia within the same experimental setting. Thus, in Experiment I, we assessed the effects of prior repeated exposure to morphine on both types of stress analgesia. In Experiment II, we investigated whether each form of footshock stress analgesia manifested tolerance with repeated administration and what effect such stress regimens had on the analgesic response to morphine in opiate-naive animals.

\section{EXPERIMENT I}

\section{Materials and Methods}

Twenty-four male Sprague-Dawley rats (300 to 400 gm) were studied. Animals were individually housed and maintained on a 12-hr light cycle with food and water available at all times. Behavioral testing was conducted during the dark phase of the light cycle. All rats were given a daily subcutaneous injection for 5 successive days. One group $(n=12)$ received morphine $(5 \mathrm{mg} / \mathrm{kg})$; the other $(n=12)$ received an equivalent volume of normal saline. Animals rested for the next 3 days to permit dissipation of any acute withdrawal effects from the morphine regimen.

To assess the influence of repeated exposure to morphine on stress analgesia, both saline- and morphinetreated animals were assigned to subgroups receiving either prolonged $(n=6)$ or brief $(n=6)$ footshock stress. We have shown previously that these stress paradigms cause naloxone-sensitive and -insensitive analgesia, respectively (Lewis et al., 1980a, b). Both stressors were inescapable footshock (2.5 mA, $60-\mathrm{Hz}$ sine waves) scrambled through the grid floor of a $23 \times 23 \times 20 \mathrm{~cm}$ Plexiglas test chamber. Prolonged footshock was $20 \mathrm{~min}$ of intermittent sine wave pulses (1 sec duration, delivered one per $5 \mathrm{sec}$ ); brief footshock was $3 \mathrm{~min}$ of continuous sine wave current.

On the test day, prestress base line pain responsiveness was measured first with a modified version of the tail flick method followed immediately by the hot plate test. Five tail flick trials were given at 1-min intervals; the mean latency of the last three trials was taken as the base line value. A limit of $7 \mathrm{sec}$ exposure to the radiant heat was imposed to minimize tissue damage to the tail. A single hot plate trial was given (water temperature set at $52.5^{\circ} \mathrm{C}$ ), and paw lick latency was measured (cf., Sherman, 1979). Rats were left on the hot plate for $60 \mathrm{sec}$ regardless of response latency. The prolonged $(20 \mathrm{~min})$ footshock regimen was begun as soon as base line latency was completed. For the brief (3-min) footshock group, a 17-min delay was imposed before stress to keep the interval between base line testing and the termination of stress constant $(20 \mathrm{~min})$ for all subjects. Immediately after either footshock stress, pain responsiveness testing was resumed. All subjects received one hot plate trial followed immediately by 12 tail flick trials, then another hot plate trial, as described above. Tail flick trials were conducted at 1 -min intervals for $9 \mathrm{~min}$, then at 2 -min intervals for three more trials. The next day, all rats were tested for analgesic responsiveness to morphine $(5 \mathrm{mg} /$ $\mathrm{kg}$, s.c.). A single hot plate trial was conducted $45 \mathrm{~min}$ after drug administration. All statistical analyses were conducted with the analysis of variance (ANOVA).

\section{Results and Discussion}

For saline-treated animals, both types of footshock stress caused pronounced analgesia in the tail flick test lasting several minutes (Fig. 1). This result conforms closely to those obtained in our previous studies (Lewis et al., $1980 \mathrm{a}, \mathrm{b})$. Prior exposure to morphine, however, differentially affected the two stress groups as measured by the tail flick test. ANOVA for repeated measures revealed no significant main effect for drug or stress but did reveal a significant drug $\times$ stress interaction $(p<$ 0.01 ). The morphine tolerance regimen clearly depressed the analgesic potency of the prolonged stress paradigm without altering that of the brief stress procedure in any way (Fig. 1).

On the hot plate trial conducted immediately after stress, strong analgesia was observed in all animals regardless of prior drug treatment or footshock paradigm. On the other hand, paw lick latencies for all animals had returned to base line by the second hot plate trial con-

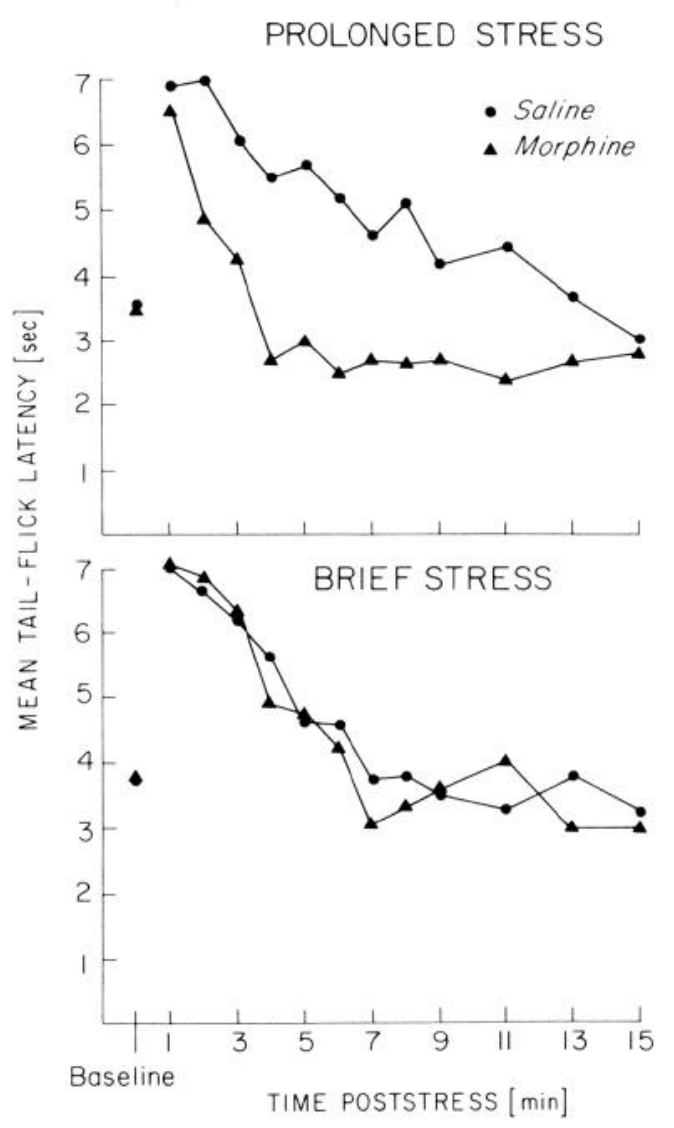

Figure 1. Effect of morphine tolerance on prolonged and brief footshock-induced analgesia. Both footshock stresses elicited elevated tail flick latencies in saline-treated control groups. Morphine tolerance significantly attenuated prolonged, but not brief, stress analgesia, indicating that only the form of stress analgesia sensitive to naloxone blockade manifests cross-tolerance. 
ducted $15 \mathrm{~min}$ after stress. The absence of group differences on this test perhaps is not surprising. Reference to the tail flick results displayed in Figure 1 suggests both that the first hot plate test was conducted before analgesia scores for the two morphine-treated stress groups had begun to diverge and that the second test was conducted after stress analgesia had already dissipated.

On the day following stress analgesia testing, both groups previously exposed to morphine displayed significantly less hot plate analgesia than saline-treated groups to the test dose of morphine $(p<0.05)$ and this did not interact with the prior stress condition. Thus, it may be concluded that these rats were at least partially tolerant to morphine the preceding day when cross-tolerance to prolonged stress, but not to brief stress, analgesia was observed.

Prior exposure to morphine versus saline did not affect base line pain responsiveness as indexed by either the tail flick or hot plate tests.

\section{EXPERIMENT II}

\section{Materials and Methods}

Thirty male Sprague-Dawley rats (300 to $400 \mathrm{gm}$ ) were studied. Animals were maintained as in Experiment I. Stress paradigms and procedures for base line and poststress tail flick testing were also as described above. Rats were assigned to one of three groups: those receiving repeated exposure to prolonged stress $(n=10)$, repeated exposure to brief stress $(n=10)$, or a nonstress control condition in which rats received equal exposure to the test environment but no footshock $(n=10)$.

On day 1, all animals were brought to the testing room and given base line tail flick trials followed by the appropriate stress procedure or a 20 -min rest interval for the nonstress controls. Immediately following the stress or rest period, 12 additional tail flick trials were conducted. For the next 12 days, rats were brought to the test room and stressed or rested as on day 1, but tail flick testing was not conducted. On day 14 , all animals were tested once again for base line and poststress pain responsiveness, as on day 1 .

On day 15 , all animals were tested for analgesic responsiveness to morphine using the hot plate method, as described in Experiment I. After determining base line paw lick latencies, we administered morphine to the animals (5 mg/kg, s.c.). Postmorphine paw lick latencies were assessed at $20,40,60,80,120$, and $180 \mathrm{~min}$ after drug injection. A week later, analgesic responsiveness to morphine was measured once again, this time using the tail flick method. To avoid a ceiling effect, the limit of exposure to radiant heat was extended from 7 to $10 \mathrm{sec}$; otherwise, testing was conducted as before. Base line tail flick latencies were determined; then rats were injected with morphine (5 mg/kg, s.c.). Postmorphine pain responsiveness was calculated as the mean latency of three tail flick trials (separated by 1-min intervals) conducted at each of the same time points after morphine injection (i.e., $20, \ldots, 180 \mathrm{~min}$ ) as were used in the hot plate test. All data were subjected to ANOVA for repeated measures and Newman-Keuls tests for specific group comparisons (Keppel, 1973).

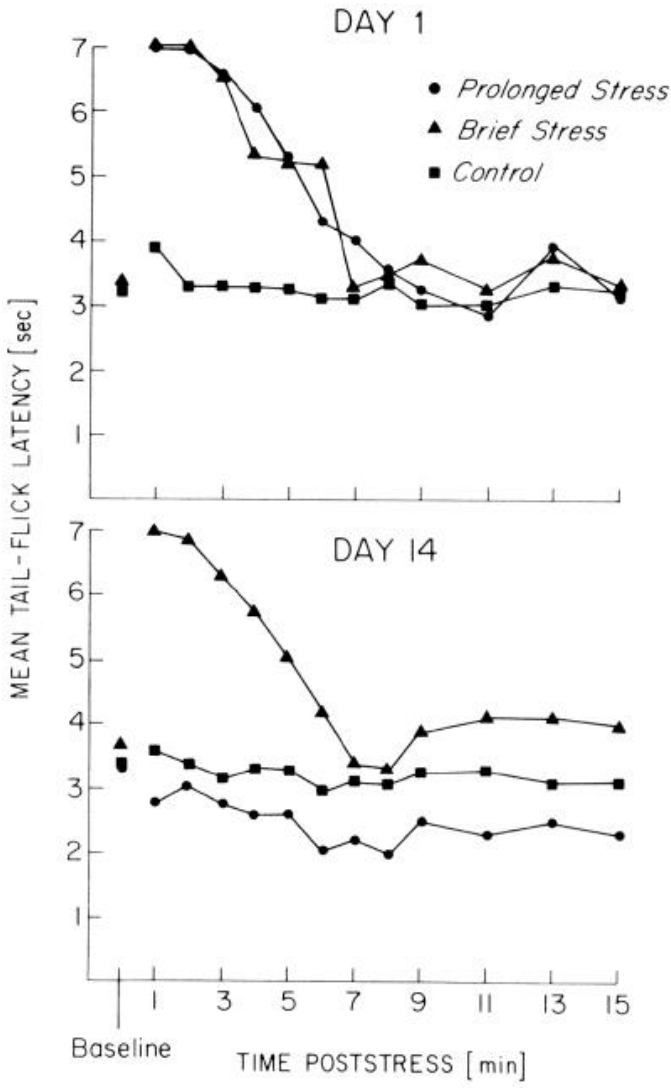

Figure 2. Development of tolerance to stress analgesia. Day 1: Both prolonged and brief footshock stress elicited significantly elevated tail flick latencies. Day 14: Only the group repeatedly exposed to prolonged footshock developed tolerance to stress analgesia.

\section{Results and Discussion}

Initial exposure to either footshock stress (Fig. 2, top) caused potent analgesia in the tail flick test $(p<0.01$, compared to nonstress controls). This finding replicates that of Experiment I and those of our earlier studies (Lewis et al., 1980a, b). After 14 days of stress, although rats in the brief footshock group continued to show strong poststress analgesia $(p<0.01$, compared to nonstress controls), those given the prolonged footshock regimen were clearly tolerant to its analgesic effect (Fig. 2, bottom). In fact, rats in the prolonged stress group had tail flick latencies markedly lower than nonstress controls on the 14 th day $(p<0.01))^{2}$ thus manifesting poststress hyperalgesia. A similar observation has been reported by Akil et al. (1976a). Prior to stress on day 14, animals in the brief stress group had significantly higher base line latencies than those in the other two groups $(p<0.05)$.

On day 15 , all animals manifested significant hot plate analgesia to the test dose of morphine (Fig. 3). ANOVA for repeated measures revealed significant main effects for stress procedure and time $(p<0.01)$. Both stress groups differed from controls overall $(p<0.05)$ but did not differ from each other. The stress $\times$ time interaction

\footnotetext{
${ }^{2}$ Due to the disparate error variance contributed by the brief stress group, this analysis was conducted on the prolonged and nonstressed groups only.
} 

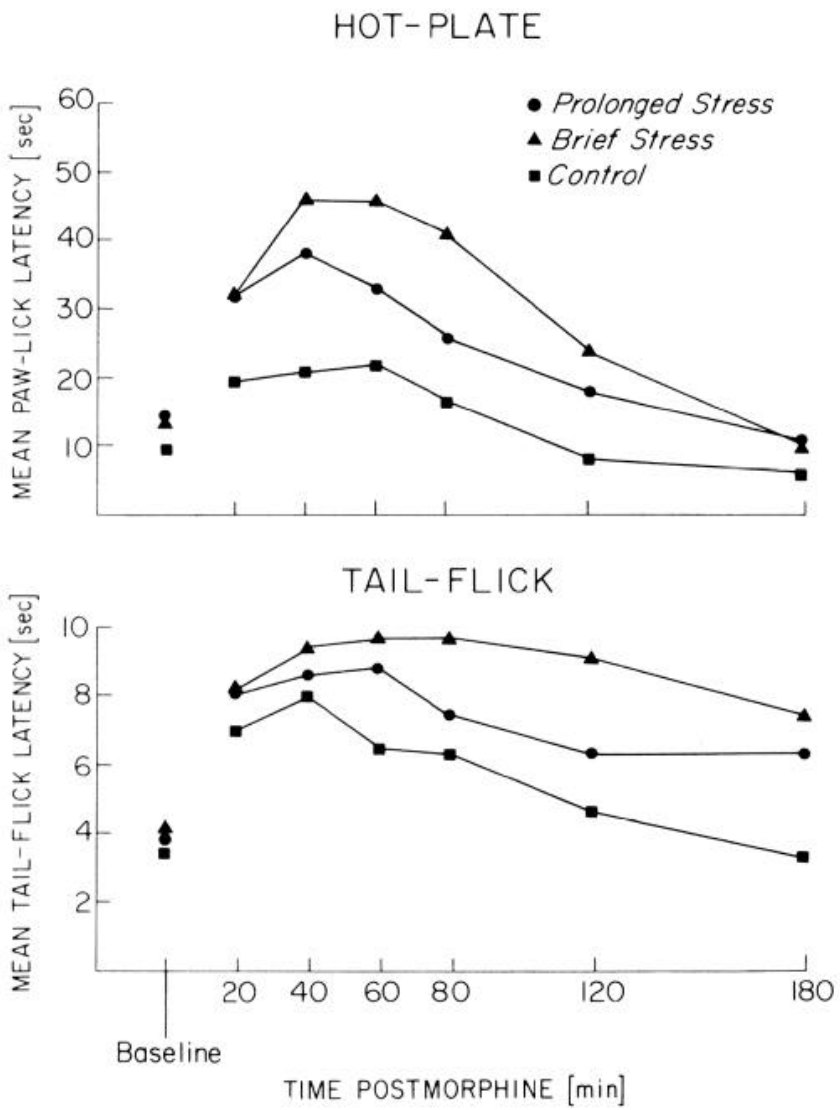

Figure 3. Effect of repeated exposure to stress on morphine analgesia. Both stress groups had significantly higher postmorphine response latencies than nonstress controls in hot plate and tail flick tests. However, the potentiation of morphine analgesia by prior stress was less pronounced in the prolonged stress group, suggesting that cross-tolerance to morphine analgesia occurred in these animals. Additionally, both stress groups had significantly higher base line latencies than controls in the two pain tests.

was not significant, precluding further statistical analysis of these data. Responsiveness to morphine was tested again 1 week later with the tail flick method. The pattern of results was extremely similar to that obtained with the hot plate test (Fig. 3). ANOVA for repeated measures revealed significant main effects for group and time and a significant group $\times$ time interaction. Specific comparisons showed the brief stress group differed from controls at 60,80 , and $120 \mathrm{~min}$, the prolonged stress group differed from controls at 60 and $120 \mathrm{~min}$, and the two stress groups differed from each other at 80 and $120 \mathrm{~min}(p<$ 0.05 ). On both hot plate and tail flick tests, the two stress groups had significantly higher base line response latencies than nonstress controls $(p<0.05)$, although they did not differ from each other.

\section{Discussion}

We have shown previously that footshock stress analgesia can be manifested in two forms, one susceptible to naloxone blockade, the other not (Lewis et al., 1980a, b). Which substrate is activated appears to depend on temporal parameters of the footshock. The results of the present investigation confirm and extend the earlier findings. In Experiment I, rats made partially tolerant to morphine displayed cross-tolerance to only that form of stress analgesia (prolonged, intermittent footshock) sensitive to naloxone antagonism; in Experiment II, tolerance was found to develop to only the naloxone-sensitive type of stress analgesia. Moreover, although prior exposure to either footshock stress facilitated morphine analgesia, this effect was attenuated in the group that had received the naloxone-sensitive form of footshock, suggesting that cross-tolerance occurred in this direction as well. Thus, the results of the present investigation, based on criteria different from those used in our earlier work, strongly support our previous contention that separate opioid and non-opioid mechanisms of stress analgesia exist (Lewis et al., 1980a).

In Experiment I, because relatively little drug was given during the morphine tolerance procedure and because stress testing followed the last morphine injection by 3 days, the diminished stress analgesia displayed by the prolonged footshock group is probably not due to acute effects of opiate withdrawal. Moreover, the fact that both stress groups received the same morphine regimen, yet only one displayed reduced stress analgesia, argues strongly for a cross-tolerance explanation. This finding illustrates the advantage to investigations such as these of studying two closely related but neurochemically different forms of stress analgesia under the same test conditions.

That tolerance developed to prolonged footshock analgesia and that cross-tolerance to it was evident in rats already tolerant to morphine are findings directly interpreted as supporting the hypothesis that this form of stress analgesia is mediated by opioid peptide binding to opiate receptors. Further support for this view derives from our earlier observation that naloxone blocks this type of stress analgesia at doses as low as $0.1 \mathrm{mg} / \mathrm{kg}$ (Lewis et al., 1980b). Another kind of analgesia presumed to be mediated by opioid peptide release, that resulting from periaqueductal gray electrical stimulation in the rat, is known now to be comparably sensitive to naloxone antagonism (Cannon et al., 1980). The cross-tolerance tests conducted in Experiment II, however, yielded results less clearly compatible with this hypothesis. Rats subjected to either prolonged or brief footshock stress later displayed a markedly facilitated analgesic response to morphine compared to nonstress controls. Thus, sensitization to morphine analgesia, apparently not crosstolerance, occurred. On the other hand, animals in the prolonged stress group (those manifesting tolerance to stress analgesia) responded to morphine with a degree of analgesia between that shown by the brief stress and nonstress groups. We suggest that the weaker sensitization to morphine shown by animals already tolerant to stress analgesia reflects the process of cross-tolerance superimposed upon the more dramatically evident process of facilitated morphine analgesia in previously stressed rats.

The intriguing potentiation of morphine analgesia by prior exposure to stress is, in fact, not without precedent in the literature. Several recent studies report enhanced opiate analgesia in rats after repeated pain or stress 
(Belenky and Holaday, 1979; Colpaert et al., 1980). Moreover, in a separate series of experiments, we have found that repeated exposure to various stressors potentiates morphine analgesia in rats already tolerant to morphine and in drug-naive animals (J. E. Sherman, manuscript in preparation). Of particular interest, Sherman found that this effect was situationally specific in that the environment in which stress and morphine were administered had to be the same for potentiation to occur. Rats stressed in the same environment where responsiveness to morphine was assessed, but not rats stressed elsewhere, not only showed potentiated morphine analgesia but also less pain sensitivity before morphine administration, i.e., conditioned analgesia (cf., MacLennan et al., 1980). These results are consistent with those of Experiment II where, however, stress and analgesia testing were always conducted in the same environment. The importance of this demonstration of situational specificity in both base line and morphine effects, suggesting a learned association between stress and environmental cues, makes unlikely the critical involvement in these phenomena of any changes due to the stress, per se. For example, repeated electric shocks might be thought to injure the animal's footpads, making tissue damage responsible for enhanced hot plate latencies. If so, however, rats stressed in an environment different from the test room should also have higher latencies, and they do not (Sherman et al., 1981).

Previous investigations of cross-tolerance between opiate and stress analgesia have yielded conflicting results, some showing cross-tolerance (Chesher and Chan, 1977; Spiaggia et al., 1979; L. Watkins, personal communication), others not (Akil et al., 1978; Bodnar et al., 1978b; Chance and Rosecrans, 1979a). The diversity of stressors and other methodological differences among these studies preclude making direct comparisons between them. In general, when footshock stress has been used, a good correspondence has been reported between sensitivity to naloxone and cross-tolerance with morphine (Chesher and Chan, 1977; L. Watkins, personal communication). However, Akil et al. (1978), using a footshock paradigm yielding naloxone-sensitive analgesia, found that rats first made tolerant to morphine by pellet implantation did not manifest cross-tolerance to stress analgesia but, on the contrary, displayed enhanced analgesic responsiveness. Similarly, Belenky and Holaday (1979) reported enhanced electroconvulsive shock-induced analgesia in rats rendered tolerant by morphine pellet implantation. Whether the use of morphine pellets or other procedural differences account for these discrepant outcomes is not yet clear.

Development of tolerance to stress analgesia and crosstolerance to morphine analgesia may reflect changes either in opiate receptor properties or in the synthesis, release, or degradation of opioid peptides. An explanation based strictly on decreased receptor sensitivity seems unlikely given that animals tolerant to stress analgesia nonetheless showed enhanced morphine analgesia (Experiment II). On the other hand, stress is known to aller both brain and plasma indices of opioid activity (Baizman et al., 1979; Chance et al., 1978, 1979b; French et al., 1978; Madden et al., 1977; Rossier et al., 1977, 1978). In fact, using footshock parameters comparable to those of the prolonged stress procedure in our work, Akil et al. (1976a) report that acute exposure to stress elicits a rise in brain opioid activity and that this effect manifests tolerance with repeated stress administration. Alternatively, development of tolerance to stress might reflect changes in other systems that normally interact with the opiate analgesia substrate. A likely candidate for such a system is the pituitary-adrenal axis known to be activated by stress and by opiates and opioid peptides (cf., for review Meites et al., 1979; Holaday and Loh, 1979). Because hypophysectomy and adrenalectomy reduce only naloxone-sensitive stress analgesia (Amir and Amit, 1979; Bodnar et al., 1979a, b; Chance et al., 1979a; Millan et al., 1980; J. W. Lewis, J. E. Sherman, and J. C. Liebeskind, manuscript in preparation) and because these lesions also modify opiate analgesia and the development of opiate tolerance (e.g., Gebhart and Mitchell, 1972; Holaday et al., $1979 \mathrm{a}, \mathrm{b})$, it seems likely that this endocrine system plays a significant role in tolerance development to opioid stress analgesia.

\section{References}

Akil, H., D. J. Mayer, and J. C. Liebeskind (1972) Comparison chez le rat entre l'analgésie induite par stimulation de la substance grise péri-aqueducale et l'analgésie morphinique. C. R. Acad. Sci. (D) (Paris) 274: 3603-3605.

Akil, H., J. Madden, R. L. Patrick, and J. D. Barchas (1976a) Stress-induced increase in endogenous opiate peptides: Concurrent analgesia and its partial reversal by naloxone. In Opiates and Endogenous Opioid Peptides, H. W. Kosterlitz, ed., pp. 63-70, Elsevier, Amsterdam.

Akil, H., D. J. Mayer, and J. C. Liebeskind (1976b) Antagonism of stimulation-produced analgesia by naloxone, a narcotic antagonist. Science 191: 961-962.

Akil, H., S. J. Watson, P. A. Berger, and J. D. Barchas (1978) Endorphins, $\beta$-LPH, and ACTH: Biochemical, pharmacological, and anatomical studies. In The Endorphins, E. Costa and M. Trabucchi, eds., pp. 125-140, Raven Press, New York.

Amir, S., and Z. Amit (1978) Endogenous opioid ligands may mediate stress-induced changes in the affective properties of pain related behavior in rats. Life Sci. 23: 1143-1152.

Amir, S., and Z. Amit (1979) The pituitary gland mediates acute and chronic pain responsiveness in stressed and non-stressed rats. Life Sci. 24: 439-448.

Baizman, E. R., B. M. Cox, O. H. Osman, and A. Goldstein (1979) Experimental alterations of endorphin levels in rat pituitary. Neuroendocrinology 28: 402-424.

Balagura, S., and T. Ralph (1973) The analgesic effect of electrical stimulation of the diencephalon and mesencephalon. Brain Res. 60: 369-379.

Belenky, G. L., and J. W. Holaday (1979) Repeated electroconvulsive shock (ECS) and morphine tolerance: Demonstration of cross-sensitivity in the rat. Soc. Neurosci. Abstr. 5: 549.

Bodnar, R. J., D. D. Kelly, A. Spiaggia, C. Ehrenberg, and M. Glusman (1978a) Dose-dependent reductions by naloxone of analgesia induced by cold-water stress. Pharmacol. Biochem. Behav. 8: 667-672.

Bodnar, R. J., D. D. Kelly, S. S. Steiner, and M. Glusman (1978b) Stress-produced analgesia and morphine-produced analgesia: Lack of cross-tolerance. Pharmacol. Biochem. Behav. 8: 661-666.

Bodnar, R. J., M. Glusman, M. Brutus, A. Spiaggia, and D. D. Kelly (1979a) Analgesia induced by cold-water stress: Attenuation following hypophysectomy. Physiol. Behav. 23: 53-62. Bodnar, R. J., D. D. Kelly, A. Mansour, and M. Glusman 
(1979b) Differential effects of hypophysectomy upon analgesia induced by two glucoprivic stressors and morphine. Pharmacol. Biochem. Behav. 11: 303-308.

Cannon, J. T., G. J. Prieto, A. Lee, and J. C. Liebeskind (1980) Antagonism of stimulation-produced analgesia by naloxone: Effects of stimulation site, dose and time. Fed. Proc. 39: 603.

Chance, W. T., and J. A. Rosecrans (1979a) Lack of crosstolerance between morphine and autoanalgesia. Pharmacol. Biochem. Behav. 11: 639-642.

Chance, W. T., and J. A. Rosecrans (1979b) Lack of effect of naloxone on autoanalgesia. Pharmacol. Biochem. Behav. 11: $643-646$.

Chance, W. T., A. C. White, G. M. Krynock, and J. A. Rosecrans (1978) Conditional fear-induced decreases in the binding of $\left[{ }^{3} \mathrm{H}\right] N$-Leu-enkephalin to rat brain. Brain Res. 141: 371-374.

Chance, W. T., G. M. Krynock, and J. A. Rosecrans (1979a) Investigation of pituitary influences on autoanalgesia. Psychoneuroendocrinology 4: 199-205.

Chance, W. T., A. C. White, G. M. Krynock, and J. A. Rosecrans (1979b) Autoanalgesia: Acquisition, blockade and relationship to opiate hinding. Fur. J. Pharmacol. 58: 461-468.

Chesher, G. B., and B. Chan (1977) Footshock induced analgesia in mice: Its reversal by naloxone and cross-tolerance with morphine. Life Sci. 21: 1569-1574.

Cobelli, D. A., L. R. Watkins, and D. J. Mayer (1980) Dissociation of opiate and non-opiate foot-shock produced analgesia. Soc. Neurosci. Abstr. 6: 247.

Colpaert, F. C., C. J. E. Niemegeers, P. A. J. Janssen, and A. N. Maroli (1980) The effects of prior fentanyl administration and of pain on fentanyl analgesia: Tolerance to and enhancement of narcotic analgesia. J. Pharmacol. Exp. Ther. 213: 418-424.

French, E. D., F. E. Bloom, C. Rivier, R. Guillemin, and J. Rossier (1978) Morphine or stress induced increases of plasma $\beta$-endorphin and prolactin are prevented by dexamethasone pretreatment. Soc. Neurosci. Abstr. 4: 408.

Gebhart, G. F., and C. L. Mitchell (1972) The effect of adrenalectomy on morphine analgesia and tolerance development in rats. Eur. J. Pharmacol. 18: 37-12.

Hayes, R. L., G. J. Bennett, P. G. Newlon, and D. J. Mayer (1978) Behavioral and physiological studies of non-narcotic analgesia in the rat elicited by certain environmental stimuli. Brain Res. 155: 69-90.

Holaday, J. W., and H. H. Loh (1979) Endorphin-opiate interactions with neuroendocrine systems. In Neurochemical Mechanisms of Opiates and Endorphins, H. H. Loh and D. H. Ross, eds., pp. 227-258, Raven Press, New York.

Holaday, J. W., M. F. Dallman, and H. H. Loh (1979a) Effects of hypophysectomy and ACTH on opiate tolerance and physical dependence. Life Sci. 24: 771-782.

Holaday, J. W., P. -Y. Law, H. H. Loh, and C. H. Li (1979b) Adrenal steroids indirectly modulate morphine and $\beta$-endorphin effects. J. Pharmacol. Exp. Ther. 208: 176-183.

Keppel, G. (1973) Design and Analysis: A Researcher's Handbook, Prentice-Hall, Inc., Englewood Cliffs, NJ.

Lewis, J. W., J. T. Cannon, and J. C. Liebeskind (1980a) Opioid and nonopioid mechanisms of stress analgesia. Science 208: 623-625.

Lewis, J. W., J. T. Cannon, J. M. Stapleton, and J. C. Liebeskind (1980b) Stress activates endogenous pain-inhibitory systems: Opioid and nonopioid mechanisms. Proc. West. Pharmacol. Soc. 23: 85-88.

Lewis, J. W., S. Caldecott-Hazard, J. T. Cannon, and J. C. Liebeskind (1981) Possible role of opioid peptides in pain inhibition and seizures. In Neurosecretion and Brain Peptides: Implications for Brain Function and Neurological
Disease, J. B. Martin, ed., Raven Press, New York, in press.

MacLennan, A. J., R. L. Jackson, and S. F. Maier (1980) Conditioned analgesia in the rat. Bull. Psychon. Soc. 15: $387-$ 390.

Madden, J., H. Akil, R. L. Patrick, and J. D. Barchas (1977) Stress-induced parallel changes in central opioid levels and pain responsiveness in the rat. Nature 265: 358-360.

Mayer, D. J., and J. C. Liebeskind (1974) Pain reduction by focal electrical stimulation of the brain: An anatomical and behavioral analysis. Brain Res. 68: 73-93.

Mayer, D. J., and D. D. Price (1976) Central nervous system mechanisms of analgesia. Pain 2: 379-404.

Mayer, D. J., T. L. Wolfle, H. Akil, B. Carder, and J. C. Liebeskind (1971) Analgesia from electrical stimulation in the brainstem of the rat. Science 174: 1351-1354.

Meites, J., I. F. Bruni, D. A. VanVugt, and A. F. Smith (1979) Relation of endogenous opioid peptides and morphine to neuroendocrine functions. Life Sci. 24: 1325-1336.

Millan, M. J., R. Przewlocki, and A. Herz (1980) A non- $\beta$ endorphinergic adenohypophyseal mechanism is essential for an analgetic response to stress. Pain 8: 343-353.

Oleson, T. D., D. A. 'Twombly, and J. C. Liebeskind (1978) Effects of pain-attenuating brain stimulation and morphine on electrical activity in the raphe nuclei of the awake rat. Pain 4: 211-230.

Oliveras, J. L., Y. Hosobuchi, F. Redjemi, G. Guilbaud, and J. M. Besson (1977) Opiate antagonist, naloxone, strongly reduces analgesia induced by stimulation of a raphe nucleus (centralis inferior). Brain Res. 120: 221-229.

Prieto, G. J., G. J. Giesler, Jr., and J. T. Cannon (1979) Evidence for site specificity in naloxone's antagonism of stimulationproduced analgesia in the rat. Soc. Neurosci. Abstr. 5: 614 .

Reynolds, D. V. (1969) Surgery in the rat during electrical analgesia induced by focal brain stimulation. Science 164: 444-445.

Rhodes, D. L., and J. C. Liebeskind (1978) Analgesia from rostral brain stem stimulation in the rat. Brain Res. 143: 521532.

Rossier, J., E. D. French, C. Rivier, N. Ling, R. Guillemin, and F. E. Bloom (1977) Foot-shock induced stress increases $\beta$ endorphin levels in blood but not brain. Nature 270: 618-620.

Rossier, J., R. Guillemin, and F. Bloom (1978) Foot shock induced stress decreases leu ${ }^{5}$-enkephalin immunoreactivity in rat hypothalamus. Eur. J. Pharmacol. 48: 465-466.

Sherman, J. E. (1979) The effects of conditioning and novelty on the rat's analgesic and pyretic responses to morphine. Learn. Motiv. 10: 383-418.

Sherman, J. E., and J. C. Liebeskind (1980) An endorphinergic, centrifugal substrate of pain modulation: Recent findings, current concepts, and complexities. In Pain, J. J. Bonica, ed., pp. 191-204, Raven Press, New York.

Sherman, J. E., J. W. Lewis, R. E. deWetter, and J. C. Liebeskind (1981) Conditioned fear enhances morphine analgesia in the rat. Proc. West. Pharmacol. Soc., in press.

Spiaggia, A., R. J. Bodnar, D. D. Kelly, and M. Glusman (1979) Opiate and non-opiate mechanisms of stress-induced analgesia: Cross-tolerance between stressors. Pharmacol. Biochem. Behav. 10: 761-765.

Watson, S. J., H. Akil, and J. D. Barchas (1979) Immunohistochemical and biochemical studies of the enkephalins, $\beta$ endorphin and related peptides. In Endorphins in Mental Health Research, E. Usdin, W. E. Bunney, Jr., and N. S. Kline, eds., pp. 30-44, Oxford University Press, New York.

Yaksh, T. L., and T. A. Rudy (1978) Narcotic analgetics: CNS sites and mechanisms of action as revealed by intracerebral injection techniques. Pain 4: 299-359. 